\title{
Challenges in Biofilm Inactivation: The Use of Cold Plasma as a New Approach
}

\author{
Graciela Brelles-Mariño ${ }^{1,2 *}$ \\ ${ }^{1}$ Biological Sciences Department, California State Polytechnic University, USA \\ ${ }^{2}$ CINDEFI, Facultad de Ciencias Exactas, Universidad Nacional de La Plata, Argentina
}

For many years, microbiologists thought of microbes as isolated entities growing apart. Actually, this is more the exception than the rule. Most microbes are "social" and prefer to live as part of communities where interactions take place [1]. Biofilms are microbial communities attached to a surface and embedded in a matrix composed of exopolysaccharides together with proteins and excreted nucleic acids.

Wherever there is a surface and some moisture, it is likely that biofilms will develop. Biofilm formation begins when free-living (planktonic) bacteria first reversibly absorb and then irreversibly attach to a surface, divide, and recruit additional planktonic cells that attach to the cells already on the surface. Therefore, the emerging biofilm can be composed of a single-species bacterium or a combination of different species. Single-species biofilms are rarely found in natural environments. More frequently, biofilms are composed of many different species of bacteria, yeasts, and fungi [2-4]. The following discussion will focus on bacterial biofilms.

Biofilms are present almost everywhere and impact all aspects of our life; in many cases their presence leads to disease, prostheses colonization, product contamination, biofouling, and equipment damage, just to mention a few effects. According to the National Institutes of Health (NIH) and The Center for Disease Control (CDC) $90 \%$ of infections in humans and $65 \%$ of nosocomial infections are due to biofilms. Biofilms have been considered responsible for plaque formation on teeth, gum disease, ear infection in children, and play a role in cystic fibrosis and Legionnaire disease, among other health problems. Biofilms contaminate many household surfaces, including toilets, sinks, and cutting boards. In industrial settings, biofilms adversely impact many processes leading to a decrease in process efficiency and end-product purity. Biofilms also contaminate water sources and cause pipe plugging. Helicobacter pylori, a microorganism responsible for gastric ulcers, have been found in pipes in drinking water systems. Therefore not only the industrial contamination is a concern but also the possibility of spreading disease by contaminated water [5].

Conventional methods of controlling free-living bacteria by chemical, physical or biological ways are often ineffective with biofilms because bacteria within the biofilm show different properties from those in planktonic life [6,7]. Biofilms demonstrate unusual resistances to nearly all forms of sterilization. These mechanisms can vary from non-genetic antibiotic resistance to phenotypic changes into persistent cells. The use of moist heat and pressure in the autoclave is still an inexpensive method for many applications. However, it cannot be applied to all situations and to every material such as biofilms in prosthetic devices within a patient. Thermosensitive materials cannot withstand autoclaving. Chemicals, such as ethylene oxide, allow lowtemperature disinfection, but ethylene oxide is both mutagenic and carcinogenic. Other chemicals, such as chlorine, are also not suitable for many applications and pose an environmental hazard and risks to human health. Radiation can be used in some but not all the cases. For all the aspects exposed above, biofilm control and removal demands the development of new strategies.
In a recent editorial from the Open Access journal Microbial \& Biochemical Technology, Dominico Schillaci discusses the challenges in the discovery of novel anti-infective agents for sthaphylococcal biofilms and three approaches used: 1)screen-based strategies involving the screening of novel compounds for biofilm inhibition, 2) target-based strategies, focused on finding or developing compounds that target pathways essential for biofilm formation, and 3) biofilm matrix targeting strategies consisting on identifying enzymes that target the biofilm matrix [8]. Although the discussion refers to staphylococcal biofilms, similar approaches could be applied to other biofilms. Current procedures to treat biofilms include the catalytic generation of biocidal species at the biofilm-substratum interface. The catalysts increase the rate of free radical generation by hydrogen peroxide and potassium monopersulphate and have been shown to be useful in the destruction of thick Pseudomonas aeruginosa biofilms $[9,10]$. However this methodology generates hazardous compounds. The use of polychromatic light to irradiate biofilms grown on glass slides coated with $\mathrm{TiO}_{2}$ has also been tested [11]. This methodology has many limitations regarding its potential applications to environmental settings and food processing environments. Antibiotic treatment has also been used in the food industry to treat meat products with sprays and washes with lactic acid and other antimicrobials. Although these treatments significantly reduce bacterial load, they do not eliminate pathogenic bacteria. The effect of different sanitizers was also studied on Listeria monocytogenes inoculated into beef and the biofilms showed more resistance to most of the sanitizers than planktonic cells [12]

A different approach to inactivate bacterial biofilms is by means of non thermal gas discharge plasmas. Plasma offers a good alternative to conventional sterilization methods since they contain a mixture of reactive agents such as free radicals, charged particles, UV photons, etc. which are effective in the destruction of planktonic microorganisms $[13,14]$. Plasma results from the energy transfer from a source, usually an electric discharge, to the surrounding gas. A part of the gas molecules is raised from their energy ground state to an excited one with a modified electron distribution. The most commonly used method of generating plasmas is by applying an electric field to a neutral gas [15]. When the energy levels of the electrons and the heavy species are high and close to each other, the plasma is referred to as "thermal plasma". If the energy of the electrons is higher than the one of the heavy species,

*Corresponding author: Graciela Brelles-Mariño, Biological Sciences Department, California State Polytechnic University, USA, E-mail: gbrelles@csupomona. edu

Received October 26, 2012; Accepted October 26, 2012; Published November 05, 2012

Citation: Brelles-Mariño G (2012) Challenges in Biofilm Inactivation: The Use of Cold Plasma as a New Approach. J Bioprocess Biotech 2:e108 doi: 10.4172/2155 9821.1000e107

Copyright: (c) 2012 Brelles-Mariño G. This is an open-access article distributed under the terms of the Creative Commons Attribution License, which permits unrestricted use, distribution, and reproduction in any medium, provided the original author and source are credited. 
the plasma is considered "cold" or "non thermal". The advantage of using atmospheric pressure plasmas is the possibility of obtaining the active agents at ambient or close to ambient temperatures $(\leq 25$ $30^{\circ} \mathrm{C}$ ) without the need of a vaccum system [16-20]. For biomedical applications, atmospheric conditions are essential because samples cannot be inserted into a vacuum chamber. Furthermore, plasma sterilization is considered safe, both for the operator and the patient [13]. In addition, it is likely that synergistic effects among the active agents result in plasma being a more effective sterilization method. These agents are well known to cause cell damage or cell death in microorganisms upon exposure to even low levels of them. Another advantage of the technology is that plasma can be generated using air making the process more cost effective.

Most studies of inactivation of microorganisms by plasma were carried out with microorganisms in free-living state and supported on abiotic surfaces that discourage or at least, are not the optimal to induce cell growth. The bactericidal effect of plasma on planktonic cells has been widely investigated [21-28]. Although plasma has been proven effective against a wide range of free-living microorganisms and even spores, there are fewer reports about the use of plasma for biofilm inactivation. The effectiveness of plasma for biofilm inactivation has been determined in the last seven years [29-36,18-20].

\section{Biofilms and Oral Health}

One of the most interesting uses of plasma is the inactivation of oral biofilms. Dental plaque biofilms consists of complex communities of oral bacteria [37], well-known to produce cavities and different forms of gum disease. One of the plasma devices used to fight oral biofilms is the plasma needle [38] which was tested against cariogenic Streptococcus mutans. A simulated dental cavity model was used to study the penetration of plasma species into cavities and the effectiveness of bacterial inactivation. The inactivation of bacteria within a radius of 5-8 $\mathrm{mm}$ after 60 seconds of treatment with the plasma needle was reported. Although results are encouraging, the experimental approach uses a one-species biofilms to simulate the dental plaque while it is known that oral biofilms are composed by several types of microorganisms [33]. In a study by Sladek [32] the antimicrobial activity of a non thermal atmospheric plasma treatment against a $S$. mutans biofilm was compared to a $0.2 \%$ chlorhexidine digluconate (CHX) mouthrinse. Results show that growth of the microbes detached from the original biofilm was not observed for up to 12 hours after treatment either with plasma or with chlorhexidine. Although the results show that plasma treatment did exhibit growth inhibitory effects against detached $S$. mutants cells, the effect depends on the presence or absence of sucrose. In fact, cells treated either with plasma or CHX in the presence of sucrose grew as well as the control. Therefore it is hard to conclude whether the effect is due to the lack of sucrose or to the antibacterial treatment.

\section{Biofilms and Food}

Fresh food (salad crops, fruits, and vegetables) frequently harbor biofilms. Fresh food has been traditionally decontaminated using chlorine [39]. However, chlorination does not significantly reduce the presence of certain pathogens such as Escherichia coli $\mathrm{O} 157$ and also poses some risks to human health. Plasma has been proven to be effective to treat fresh food that cannot be treated by other methods without inducing changes in the texture, color, palatability, or quality of the food, such as nutrient content and textural qualities [34]. In most of the cases, plasma has been applied to planktonic bacteria. However, there are some reports about the use of plasma to treat biofilms on fresh products. Atmospheric Pressure Glow Discharges (APGD) have been shown to inactivate biofilm-forming bacterium Pantoea agglomerans on bell peppers (Capsicum annuum) without causing thermal damage to fresh food [34]. These authors reported two orders of log reduction which is a good baseline point for safety control since food does not require the level of inactivation of medical devices. A drawback is the study is that the authors did not study biofilms onto bell peppers but on membrane to mimic it. Reductions of greater than 5 logs was obtained for pathogens such as Salmonella, Escherichia coli O157:H7, Listeria monocytogenes, and Staphylococcus aureus on food. A key limitation for cold plasma is the largely unexplored impacts of cold plasma treatment on the sensory and nutritional qualities of treated foods [40]. The decontamination potential of plasma was also assessed on shell eggs experimentally inoculated with Salmonella enteritidis and Salmonella typhimurium, and plasma-treated at room temperature. No significant negative effects of the gas plasma were observed on the egg quality traits [41].

\section{Other Biofilms}

It has been reported that Chromobacterium violaceum biofilms can be inactivated by exposing them to an atmospheric pressure plasma jet for short exposure times and that longer times are required to completely destroy biofilm-forming cells [19]. The methodology has proven effective to inactivate more than $99 \%$ of bacterial cells after a 5-minutes exposure to plasma. Physiological and microscopy techniques suggest that longer exposure times are needed to complete eliminate these organisms.

Glidarc in humid air is a simple technique that operates at atmospheric pressure and produces non-thermal plasma by means of gliding electrical discharges . It has been proven effective against vegetative forms of bacteria under direct discharge [42,31] and postdischarge conditions [43]. Kamgang-Youbi et al. [41] have used a novel approach consisting on the production of a disinfecting solution obtained by exposing distilled water to gliding arc discharges. The authors claim that the effect is mostly due to the radical species present in the glidarc plasma plume, $\mathrm{OH}$ and $\mathrm{NO}$, when humid air is the working gas, and precursors of other active species in water such as $\mathrm{NO}_{2}-, \mathrm{NO}_{3}-$ and $\mathrm{H}_{2} \mathrm{O}_{2}$. This plasma activated water (PAW) has been found to be effective against planktonic and adherent Hafnia alvei and other planktonic microorganisms [43].

\section{Concerns about Viability}

One of the major criticisms about the literature dealing with plasma-assisted biofilm inactivation is that the killing ability of plasma is assessed by counting the colonies formed after plasma treatment. A proper assessment should include the determination of the viability status of the bacterial population. Traditionally, the effectiveness of plasma as a bacterial killing agent has been measured by counting CFUs of a plasma-treated sample and calculating the amount of surviving cells (reviewed in [1]). This approach relies only on the presence of culturable cells but does not take into account that cells might still be alive, although non-culturable, after plasma treatment. This may have catastrophic consequences if microorganisms that are assumed dead, are pathogenic ones who may retain virulence even when they are nonculturable [44]. Plasma-mediated biofilm inactivation may proceed through a first step in which bacterial cells might enter a Viable-ButNon-Culturable (VBNC) state. Bacteria enter into this dormant, VBNC state in response to one or more environmental stresses, which might otherwise be ultimately lethal to the cell. This survival mechanism has been reported for many gram-negative organisms [45-47]. Van 
den Bedem et al. [33], used a dual fluorescence staining to study the number of dead and surviving species on the microscopic slides. A similar approach was used by Joaquin et al. [19], in the study of the inactivation of Chromobacterium violaceum biofilms. Joaquin et al. [19], carried out complementary techniques in order to study viability after plasma treatment. These techniques included the estimation of the physiological status of the cell through Adenosine Triphosphate (ATP) estimation; Atomic Force Microscopy (AFM) and fluorescence microscopy to determine the viability of biofilm-forming-cells and their morphological changes after plasma treatment. The presence of living biofilm-forming bacterial cells after short exposures to plasma was reported. The results suggest that cells go through a sequential set of physiological and morphological changes before becoming inactivated by plasma. This study was instrumental for implications for plasma applications to biofilms and indicates that longer treatments are necessary to ensure complete inactivation/sterilization.

Several authors in the last years reported the use of probes and carried out viability tests after plasma treatment. Most of those studies have been carried out with planktonic cells. Moreau, et al. [42], used life/dead probes and determined the absence of viable but non culturable resistant forms when the planktonic plant pathogen Erwinia spp. was treated with plasma. Rowan, et al. [48], applied scanning electron microscopy, image analysis, and a fluorescent viability stain to assess lethal and sublethal injury in food-borne bacteria exposed to Pulsed-Plasma Gas Discharges (PPGD). The fluorescent probe was used for enumerating actively respiring cells of Campylobacter jejuni, Escherichia coli, Listeria monocytogenes, Staphylococcus aureus and Salmonella thyphimurium [48]. These authors reported a good agreement between the use of the respiratory staining and direct colony counting for enumerating untreated bacteria. However there was a 1-3 log-unit differences in surviving cell numbers per $\mathrm{mL}$ for test organisms subjected to plasma treatment. These surviving, treated-cells were also altered at the cellular level when examined by scanning electron microscopy therefore showing the need to use viability tests before drawing conclusions. These authors showed that plasma-treated cells that are unable to grow on selective laboratory-based culture media are still able to respire. They refer to this state as a sublethal injury. For plasma-assisted biofilm inactivation, it has been reported that cells remain metabolically active and intact while non-culturable after short exposure to plasma $[19,36]$. In summary, the problem of viability has to be always addressed before drawing conclusions.

\section{Concluding Remarks}

The results discussed are an evidence of the potential use of gas discharge plasma to inactivate bacterial biofilms. The technology is clean and reported to be safe for both the patient and the operator. In any case, care has to be taken before drawing conclusions about the complete removal of biofilms based solely on culturability assessment. A single cell detached from a biofilm is able to attach to a surface and trigger the development of a new mature biofilm. Therefore, if the technology is to be applied to pathogenic organisms in health-related settings, this aspect is particularly crucial to prevent recontamination of surfaces. This problem can be easily solved if viability experiments are carried out at the same time.

The technology is still somehow expensive compared to other sterilization methods. However, as most of those methods are ineffective towards biofilms or cannot be applied to all circumstances, the use of plasma still offers many promising opportunities for application. In addition, plasma generation in air offers an excellent way of minimizing costs. In summary, cold atmospheric pressure plasmas represent an interesting alternative to traditional biofilm removal/sterilization techniques.

\section{References}

1. Brelles-Mariño G (2010) Bacterial Biofilm Inactivation by Gas-Discharge Plasmas. In: Brelles-Mariño G (2010) Biological and Environmental Applications of Gas Discharge Plasmas. Nova Science Publisher.

2. Costerton JW (1999) Introduction to biofilms. Int J Antimicrob Ag 11: 217-221.

3. Ramage G, Saville SP, Thomas DP, Lopez-Ribot JL (2005) Candida Biofilms: an Update. Eukaryot Cell 4: 633-638.

4. Martinez LR, Casadevall A (2006) Cryptococcus neoformans cells in biofilms are less susceptible than planktonic cells to antimicrobial molecules produced by the innate immune system. Infect Immun 74: 6118-6123.

5. Park SR, Mackay WG, Reid DC (2001) Helicobacter sp. recovered from drinking water biofilm sampled from a water distribution system. Water Res 35: $1624-1626$

6. Hoyle BD, Costerton JW (1991) Bacterial resistance to antibiotics: the role of biofilms. Prog Drug Res 37: 91-105.

7. Stewart PS, Costerton JW (2001) Antibiotic resistance of bacteria in biofilms Lancet 358: 135-138.

8. Schillaci D (2011) Staphylococcal Biofilms: Challenges in the Discovery of Novel Antiinfective Agents. J Microbial Biochem Technol.

9. Wood P, Jones M, Bhakoo M, Gilbert P (1996) A Novel Strategy for Contro of Microbial Biofilms through Generation of Biocide at the Biofilm-Surface Interface. Appl Environ Microbiol 62: 2598-2602.

10. Wood P, Caldwell DE, Evans E, Jones M, Korber DR, et al. (1998) Surfacecatalysed disinfection of thick Pseudomonas aeruginosa biofilms. J Appl Microbiol 84: 1092-1098.

11. Rajagopal G, Maruthamuthu S, Mohanan S, Palaniswamy N (2006) Biocida effects of photocatalytic semiconductor TiO2. Colloids Surf B Biointerfaces 51 : 107-111.

12. Stopforth JD, Samelis J, Sofos JN, Kendall PA, Smith GC (2002) Biofilm formation by acid-adapted and non-adapted Listeria monocytogenes in fresh beef decontamination washings and its subsequent inactivation with sanitizers J Food Prot 65: 1717-1727.

13. Moisan M, Barbeau J, Moreau S, Pelletier J, Tabrizian M, et al. (2001) Lowtemperature sterilization using gas plasmas: a review of the experiments and an analysis of the inactivation mechanisms. Int J Pharm 226: 1-21.

14. Moisan M, Barbeau J, Crevier MC, Pelletier J, Philip N, et al. (2002) Plasma sterilization: Methods and mechanisms. Pure Appl Chem 74: 349-358.

15. Conrads H, Schmidt M (2000) Plasma generation and plasma sources. Plasma Sources Sci T 9: 441-454.

16. Laroussi M (1996) Sterilization of contaminated matter with an atmospheric pressure plasma. IEEE T Plasma Sci 24: 1188-1191.

17. Montie TC, Kelly-Wintenberg K, Roth JR (2000) An overview of research using the one atmosphere uniform glow discharge plasma (OAUGDP) for sterilization of surfaces and materials. IEEE T Plasma Sci 28: 41-50.

18. Abramzon N, Joaquin JC, Bray J, Brelles-Mariño G (2006) Biofilm Destruction by RF High-Pressure Cold Plasma Jet. IEEE T Plasma Sci 34: 1304-1309.

19. Joaquin JC, Kwan C, Abramzon N, Vandervoort K, Brelles-Mariño G (2009) Is gas-discharge plasma a new solution to the old problem of biofilm inactivation? Microbiology 155: 724-732.

20. Zelaya AJ, Stough G, Rad N, Vandervoort K, Brelles-Mariño G (2010) Pseudomonas aeruginosa Biofilm Inactivation: Decreased Cell Culturability Adhesiveness to Surfaces, and Biofilm Thickness upon High-Pressure Nonthermal Plasma Treatment. IEEE Trans Plasma Sci 38: 3398- 3403.

21. Becker K, Abramzon N, Panikov NS, Crowe R, Ricatto PJ, et al. (2002) Destruction of bacteria using an atmospheric-pressure dielectric capillary electrode discharge plasma. International Conference on Plasm Science.

22. Halfmann H, Bibinov N, Wunderlich J, Awakowicz P (2007) A double inductively coupled plasma for sterilization of medical devices. J Phys D Appl Phys 40: 4145-4154. 
Citation: Brelles-Mariño G (2012) Challenges in Biofilm Inactivation: The Use of Cold Plasma as a New Approach. J Bioprocess Biotech 2:e107 doi: 10.4172/2155-9821.1000e107

23. Panikov NS, Paduraru S, Crowe R, Ricatto PJ, Christodoulatos C et al. (2002) Destruction of Bacillus subtilis Cells Uising An Atmospheric-Pressure Dielectric Capillary Electrode Discharge. IEEE Trans Plasma Sci 30: 1424-1428.

24. Park BJ, Lee DH, Park JC, Lee IS, Lee KY, et al. (2003) Sterilization using a microwave-induced argon plasma system at atmospheric pressure. Phys Plasmas 10: 4539-4544.

25. Purevdorj D, Igura N, Ariyada O, Hayakawa I (2003) Effect of feed gas composition of gas discharge plasmas on Bacillus pumilus spore mortality. Let Appl Microbiol 37: 31-34.

26. Sladek REJ, Stoffels E, Walraven R,Tielbeek PJA, Koolhoven RA (2004) Plasma treatment of dental cavities: a feasibility study. IEEE Trans Plasma Sci 32: $1540-1543$.

27. Sladek REJ, Stoffels E (2005) Deactivation of Escherichia coli by the plasma needle. J Phys D Appl Phys 38: 1716-1721.

28. Niemira BA, Sites J (2008) Cold plasma inactivates Salmonella Stanley and Escherichia coli O157:H7 inoculated on golden delicious apples. J Food Prot 71: 1357-1365.

29. Akishev YS, Grushin ME, Karalnik VB, Monich AE, Pan'kin MV, et al. (2005) Sterilization/decontaminations of physiological solution and dry surface by nonthermal plasma created in bubbles and jet. In: Proc of the 2nd International Workshop on Cold Atmospheric Pressure Plasmas, 69-72.

30. Akishev Y, Grushin M, Karalnik V, Trushkin N, Kholodenko V, et al. (2008) Atmospheric-pressure, nonthermal plasma sterilization of microorganisms in liquids and on surfaces. Pure Appl Chem 80: 1953-1969.

31. Kamgang JO, Briandet R, Herry JM, Brisset JL, Naïtali M (2007) Destruction of planktonic, adherent and biofilm cells of Staphylococcus epidermidis using a gliding discharge in humid air. J Appl Microbiol 103: 621-628.

32. Sladek RE, Filoche SK, Sissons CH, Stoffels E (2007) Treatment of Streptococcus mutans biofilms with a nonthermal atmospheric plasma. Lett Appl Microbiol 45: 318-323.

33. Bedem LJMVD, Sladek REJ, Steinbuch RM, Adamowicz ES (2005) Plasma treatment of $\mathrm{S}$. mutans biofilms cultured in a simulated dental cavity model. Proceedings of the XXVIIth ICPIG Meeting

34. Vleugels M, Sharma G, Deng XT, Greenacre E, Brocklehurst T et al. (2005) Atmospheric plasma inactivation of biofilm-forming bacteria for food safety control. IEEE Trans Plasma Sci 33: 824-828.

35. Brelles-Mariño G, Joaquin JC, Bray J, Abramzon N (2005) Gas Discharge Plasma as a Novel Tool for Biofilm Destruction. International Workshop on Cold Atmospheric Pressure Plasmas.
36. Vandervoort KG, Abramzon N, Brelles-Mariño G (2008) Plasma Interactions with Bacterial Biofilms as Visualized through Atomic Force Microscopy. IEEE Trans Plasma Sci 36: 1296-1297.

37. Zelaya A, Vandervoort K, Brelles-Mariño G (2012) Battling Bacterial Biofilms with Gas Discharge Plasma. In: NATO Science for Peace and Security Series 135-148.

38. Stoffels E, Flikweert AJ, Stoffels WW, Kroesen GMW (2002) Plasma needle: non-destructive atmospheric plasma source for fine surface treatment of (bio) materials. Plasma Sources Sci T 11: 383-388

39. Delaquis PJ, Stewart S, Toivonen PMA, Moyls AL (1999) Effect of warm, chlorinated water on the microbial flora of shredded iceber lettuce. Food Res Int 32: 7-14.

40. Niemira BA (2012) Cold plasma decontamination of foods. Annu Rev Food Sc Technol 3: 125-142.

41. Kamgang-Youbi G, Herry JM, Brisset JL, Bellon-Fontaine MN, Doubla A, et al. (2008) Impact on disinfection efficiency of cell load and of planktonic/adherent/ detached state: case of Hafnia alvei inactivation by Plasma Activated Water. Appl Microbiol Biotechnol 81: 449-457.

42. Moreau M, Feuilloley MG, Orange N, Brisset JL (2005) Lethal effect of the gliding arc discharges on erwinia spp. J Appl Microbiol 98:1039-1046.

43. Kamgang-Youbi G, Herry JM, Bellon-Fontaine MN, Brisset JL, Doubla A et al. (2007) Evidence of temporal postdischarge decontamination of bacteria by gliding electric discharges: application to Hafnia alvei. Appl Environ Microbio 73: 4791-4796

44. Du M, Chen J, Zhang X, Li A, Li Y, et al. (2007) Retention of Virulence in a Viable but Nonculturable Edwardsiella tarda Isolate. Appl Environ Microbiol 73 1349-1354.

45. Oliver JD (1993) Formation of viable but nonculturable cells. In: Starvation in bacteria, pp. 239-272. Edited by S. Kjelleberg. New York: Plenum Press.

46. Colwell RR, Huq A (1994) Vibrios in the environment: viable but nonculturable Vibrio cholera. In: Vibrio cholerae and cholera: molecular global perspectives. T. Kaye (Ed). Proceedings of the American Society for Microbiology.

47. Day AP, Oliver JD (2004) Changes in membrane fatty acid composition during entry of Vibrio vulnificus into the viable but nonculturable state. J Microbiol 42 $69-73$

48. Rowan NJ, Espie S, Harrower J, Farrell H, Marsili L, et al. (2008) Evidence of lethal and sublethatl injury in food-borne bacterial pathogens exposed to highintensity pulsed-plasma gas discharges. Lett Appl Microbiol 46: 80-86. 